\title{
HISPANISMO EN ÁFRICA SUBSAHARIANA MÁS ALLÁ DE LA COLONIA: UNA APROXIMACIÓN A LA LITERATURA HISPANO-CAMERUNESA ${ }^{1}$
}

\author{
POR \\ Alain Lawo-SuKam \\ University of Texas A\&M
}

La literatura hispano-camerunesa se ubica dentro de la literatura africana en lengua española y atestigua el constante crecimiento del español fuera del mundo hispánico. ${ }^{2}$ No fue sino hasta mediados del los años noventa que la literatura hispanoafricana empieza a cobrar importancia en el debate teórico y crítico en torno a la literatura africana. Al hablar de la literatura hispanoafricana me refiero tradicionalmente a las antiguas posesiones españolas en África como Guinea Ecuatorial y el Sahara Occidental. ${ }^{3}$ El ostracismo de la literatura hispanoafricana resultó en cierta medida de la importancia del francés, inglés y en cierta medida del portugués en el continente africano; siendo Guinea Ecuatorial el único país de habla española. La atención que estaba empezando a recibir la literatura hispanoafricana surgió del afán de re-definir y re-pensar el concepto del hispanismo literario en su conjunto. Este fenómeno que ocurrió tanto en los Estados Unidos como en España era la labor de algunas revistas literarias y congresos internacionales en que participaron investigadores literarios de todo el mundo. Como bien lo afirma Mbare Ngom Fayé:

\footnotetext{
1 Quisiera dirigir mis sinceros agradecimientos a la Sra. Nanan Njene Toure por enviarme desde España la antología Equiniccio y El carro de los dioses que no se podía conseguir en los canales literarios comunes y sobre todo aquí en los Estados Unidos de América. Gracias también a la Profesora Esther Quintana por sus preciosas observaciones.

2 Ha habido muchas expresiones para aludir a la literatura africana en español. Donato Ndongo-Bidyoko (1998) la llama "literatura hispano-africana" para referirse a la literatura de Guinea Ecuatorial. Mbare Ngom (2003) utiliza el término de "Literatura africana hispana" para describir las obras de los escritores africanos que se sirven del español como forma de expresión artística. En el marco de este estudio, uso el término "Literatura hispano-africana" para referirme a la producción literaria de los escritores nativos de los territorios colonizados por España (Guinea Ecuatorial y el Sahara Occidental); y la "Literatura africana en lengua española" para las obras de los escritores africanos no-hispanos que escriben en español. Estas distinciones semánticas e históricas sirven para diferenciar a los autores ecuato-guineanos y saharauis de los demás escritores africanos que usan el español como idioma artístico.

3 Aunque el Sahara Occidental no ha obtenido su independencia de Marruecos, mantiene el español como la segunda lengua oficial detrás del hasanía. Se convierte así en el único territorio árabe de habla hispana.
} 
En Estados Unidos, dos acontecimientos claves marcaron un hilo extremadamente importante en los estudios de la literatura africana en español. El primero es la publicación del número especial monográfico de la revista Afro-Hispanic Review, dedicado a la literatura africana en español; y por otro, la celebración del Congreso Internacional de literatura y cultura en torno al tema reflexión "Spain in Africa and Latin America: The Other Face of Literary Hispanism" en la Universidad de Missour en Columbia en mayo de 1999. En España, el Primer Encuentro de Escritores Africanos en Lengua Española, reunido en Murcia del 27 al 29 de noviembre de 2000 , seguido días más tarde de las I Jornadas de Literatura Hispanoafricana en Madrid se situán dentro de ese marco de creciente interés por la literatura africana en español. (111)

A la revista Afro-Hispanic Review (2000) a que alude Mbare Ngom, añadimos la contribución importante del trimestral África 2000 fundado en 1985 por el centro Cultural Hispano-Guineano en Malabo, y de la Editorial Puentepalo (España) que se ha dedicado a publicar antologías sobre la literatura africana en español (Poesía saharaui contemporánea, Equinoccio y El Carro de los Dioses). En julio del 2008, la Universidad de Howard (Washington DC) organizó un seminario de cinco semanas sobre la literatura de Guinea Ecuatorial patrocinado por la National Endowment for the Humanities. El siguiente año, en abril del 2009, la Universidad de Hofstra hospició una conferencia internacional sobre la Guinea Ecuatorial. Todos estos encuentros literarios son testimonio del interés cada vez más creciente de la literatura hispanoafricana. El estudio de los escritores saharauis y de Guinea Ecuatorial está enriqueciendo paulatinamente la literatura africana e hispana. ${ }^{4}$

Aunque se han escrito artículos y libros críticos sobre la literatura hispanoafricana, sigue siendo un campo en vías de desarrollo en comparación con la literatura francoafricana, angloafricana o luxoafricana. Sin embargo, se está desarrollando paralelamente una literatura africana en lengua española de autores no procedentes de las antiguas colonias españolas sino de las francesas e inglesas. ${ }^{5} \mathrm{Si}$ bien esta literatura

\footnotetext{
Sobre la literatura hispanoafricana, se ha escrito o publicado alrededor de un centenar de artículos/ ensayos, algunas tesis doctorales, libros críticos y antologías. En el caso de la literatura de Guinea Ecuatorial se distinguen: Diálogos con Guinea Ecuatorial: Panorama de la literatura guineoecuatoriana de expresión castellana a través de sus protagonistas de Mbare Ngom; la Literatura emergente en español: Literatura de Guinea Ecuatorial de Sosthène Onomo y Otabela Mewolo; La formación de la identidad en la novela hispano-africana: 1950-1990 (Tesis doctoral de Jor Salvo, Escritores marroques de expresion español Escritores marroquíes de expresión española: el grupo de los 90 (1997) a: el grupo de los 90 (1997) Flat St Univer ex (1997) Eloida Stac Univeries de expesion esper. antologías y obras críticas: Mohamed Bouissef Rekab, Sergio Macías Chakor, Muhammad. Literatura marroqui en lengua castellana y Jacinto López Gorge, Nueva antología de relatos marroquies.

Además de la producción literaria hispanocamerunesa, citamos los poemarios del senegalés Sidi Seck Voces de Kora y Las sombras en pos del tamarindo; Los cantos del Sahel del poeta Bégong-Bodol
}

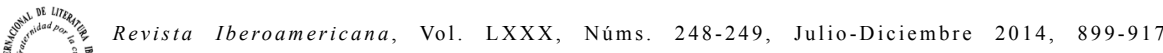
CDD no es nueva, ha recibido poca atención en los debates hispanos. Este fenómeno se debe a variadas circunstancias como la conceptualización tradicional (en los círculos académicos) de las expresiones "literatura hispanoafricana" o "literatura africana hispana" que se ha limitado a la Guinea Ecuatorial y al Sahara Occidental como espacio de estudio por la herencia colonial y lingüística. A eso se suman la poca solvencia económica de los escritores (no-hispanos), la escasa circulación de sus obras en el mercado internacional y la ignorancia o falta de voluntad (por parte del canon literario español) de incorporar dicha literatura en el acervo cultural hispano.

Este estudio se concentra en el caso particular de la República de Camerún, uno de los países africanos de habla francesa e inglesa que ha desarrollado una tradición literaria en lengua española desde los años ochenta. La literatura hispanocamerunesa es una literatura de representación y resistencia: representación del modus vivendi de pueblo camerunés y africano; y resistencia a la dominación neocolonial, al egocentrismo eurocéntrico y las injusticias. Esta literatura se ubica, en cierta medida, dentro del molde conceptual de la poscolonialidad como lo concibe J.Jorge Klor de Alva, "a form of contestatory/oppositional consciousness, emerging from either preexisting imperial, colonial, or ongoing subaltern conditions, which fosters processes aimed at revising the norms and practices of antecedent or still vital forms of domination" (245).

Para entender la literatura hispanocamerunesa, es imprescindible hacer hincapié en la historia de la literatura en lengua española en África no-hispana, cuyo origen se remonta a los años treinta en Madagascar y bajo la pluma de Jean-Joseph Rabearivelo, compuso en 1935 su primer poemario Vientos de la mañana. A pie de nota de "El español en Madagascar” Guillermo Pié Jahn e Irina Razafimbelo notan que:

Jean-Joseph Rabearivelo(Antananarivo, 1901?-1937), primer escritor en lengua español del África subsahariana, décadas antes de que naciera la literatura ecuatoguineana. Rabearivelo es la figura literaria más importante de Madagascar y uno de los más conocidos y reputados escritores francófonos. Aprendió español de forma autodidacta en el Antananarivo colonial y compuso hacia 1935 el poemario titulado Vientos de la mañana. Devoto de Góngora, a quien tradujo al malgache, siendo el primer traductor de textos literarios españoles a una lengua africana, y «amigo espiritual» de Lorca y Aberti, se carteó durante años con el intelectual mexicano Alfonso Reyes. En uno de sus poemas se confiesa dividido entre tres culturas: la malgache, la francesa y la española. (96)

La importancia del español en la isla creció con la revolución de 1972 y el fomento de estudio del español en los institutos y las universidades. Es de interés mencionar que el nacimiento de la literatura africana en lengua española en Madagascar se yuxtapone a la

Betina de la República Centroafricana y los poemas sueltos del hispanista egipcio Saifunddin Rahhal y de los tunecinos Hedi Oueslati y Ahmed Tlili.

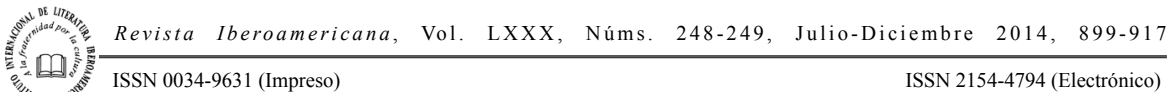


presencia de hispanistas en la capital Antananarivo en los años treinta (Pié y Razafimbelo 93). La difusión de la lengua española por los hispanistas era crucial para el desarrollo del español en la África pre y poscolonial. A esta labor de los hispanistas se añade la ayuda del gobierno español (por medio del Ministerio de Asuntos Exteriores y de Cooperación, la Agencia Española de Cooperación Internacional, las embajadas, los centros culturales y el Instituto Cervantes) y el papel importante de las relaciones y cooperaciones entre los países africanos y los demás países hispanoamericanos. Hoy en día el español es materia de enseñanza en la mayoría de los institutos y universidades en el continente. Por ejemplo, algunas universidades en Camerún, Senegal, Costa de Marfil, Gabón, Kenia, Tanzania, Suráfrica y Egipto se han dotado de Departamentos, Subdepartamentos y Programas de Español que ofrecen cursos tanto al nivel de licenciatura o maestría como de doctorado. ${ }^{6}$ Este espacio lingüístico y cultural favoreció la germinación de generaciones de hispanistas (intelectuales, docentes y literatos) que mantuvieron y siguen manteniendo viva la llama del español en el continente.

El desarrollo de la literatura hispanocamerunesa se debe en gran parte al fomento (en el sistema educativo) del español como una de las lenguas extranjeras al lado del alemán e italiano. El español se introduce en la enseñanza secundaria en 1951, en los estudios universitarios en 1963 y culmina con la institución de la diplomatura en 1977 y luego la licenciatura y cursos de posgrado en el Departamento de Estudios Ibéricos e Iberoamericanos en la Universidad de Yaundé I. La presencia del español en Camerún sigue creciendo con la ayuda de la Embajada de España, del Centro Cultural Español, de la Agencia Española de Cooperación Internacional (AECI). Aunque el interés por el español depende de motivos personales y varía de una persona a otra, ciertos factores pueden explicar su atracción entre la población: el amor por la cultura española e hispanoamericana (lengua, literatura, música, baile, arte, etc...); la influencia del fútbo (soccer) con la participación de muchos jugadores cameruneses en la liga española Carlos Kameni, Modeste M'bami, Pierre Webo sin olvidar al ex-FC barcelonés Samuel Eto'o); la posibilidad de ser funcionario y docente del primer y segundo ciclo en la enseñanza secundaria (lo que también proporciona una estabilidad económica); seguir estudios o una carrera profesional en países hispanos; establecer contactos comerciales con empresas hispanas; la proximidad con Guinea Ecuatorial y los intercambios entre ambos países. A eso se suman otros factores menores como la cercanía del español a francés y el hecho de que no tiene el estigma de ser una lengua colonial como el francés,

\footnotetext{
Podemos mencionar la Universidad de San Luís, la de Cheick Antar Diop y la de Dakar en Senegal; La Universidad de Yaundé I, La Escuela Normal Superior de Yaunde y la Universidad de Duala en Camerún; la Universidad de Ciudad del Cabo, la Universidad de Witwatersrand en Johannesburgo en Sudáfrica y La Universidad Ain-Shams en Egipto entre otras tantas universidades en el continente. Para explorar Lemática de la lengua española en Africa, consultar la Enciclopedia del Español en el Mundo (2006).
}

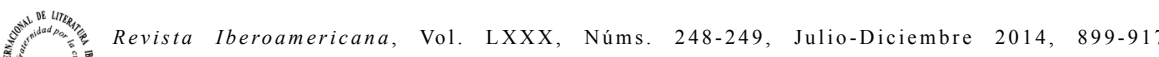

el inglés o el alemán como lo corroboran Fátima Godínez Gonzales, Martha Martínez Hernando y César Rodríguez Dopico.

Es dentro del contexto de crecimiento de la enseñanza del español que nace la literatura hispanocamerunesa cuyos pioneros son: Céline Clémence Magnéché Ndé, Boniface Ofogo, Inongo-vi-Makomé, Magloire Mol Nang, Guy Merlin Nana Tadoun, Robert Marie Johlio y Germain Metamo. A éstos se asocian la generación de escritores emergentes como Alain Lawo-Sukam y Romual-Achille Mahop Ma Mahop. ${ }^{8}$ La mayoría de los escritores se beneficiaron de la enseñanza del español en los institutos y la Universidad de Yaúnde I/Escuela Normal Superior y obtuvieron también becas para realizar investigación en lengua y literatura. Además de ser escritores, casi todos son docentes/catedráticos, lo que les permite superar el hambre y mantener a su familia. Debido a la crisis económica, resulta difícil sobrevivir en los países subdesarrollados como mero escritor.

A diferencia de la literatura ecuatoguineana, la hispanocamerunesa es poscolonial ya que empieza a aparecer después de la independencia de Camerún en 1961 abarca tanto la poesía como la novela y el cuento. Las primeras obras se remontan a mediados de los ochenta con la publicación en 1985 de Hijo Varón del escritor Germain Metamo, Bemama (1988) y Akono y Belinga (1988) de Inongo-vi Makome. La mayoría de la producción literaria hispanocamerunesa se produce a finales de los noventa y principios del 2000 con la publicación de: Rebeldía (1996) y Nativas (2008) de Inongo-vi-makomé; El esqueleto de un gigante (1998) de Robert Marie Jolhio y Pedro Pablo Viñuales; Voces de mi tierra (1999) de Germain Metamo; Horizontales (2005) de Guy Merlin Nana Tadoun; ¿Verdad que esto ocurrió? (2004) de Cécile Clémente Magnéché; La huérfana y otros (2004) de Magloire Mol Nang; Una vida de cuento (2006) de Boniface Ofogo Nkama; "Cantos a África (Colección de poemas)" publicado en Afro-Hispanic Review (2003), "Tres poemas" publicado también en Afro-Hispanic Review (2004) y "La voz del pueblo africano (Colección de poemas)" publicado en la revista El collar de la paloma (2007).

Los escritores hispanocameruneses se dividen en dos categorías: unos radican en el Occidente como Inongo-vi-Makomé, Guy Merlin Nana Tadoun, y Boniface Ofogo

Mi interés por el español surgió en la escuela secundaria por la lectura de la obra (en dibujo) de $E$ Ingenioso Hidalgo Don Quijote de la Mancha y por mi amor hacia la música cubana como la salsa y el merengue. Nunca hubiera creído que veinte años más tarde iba a ser catedrático de Estudios Hispánicos y de la Diáspora Africana en la Universidad de Texas A\&M en los Estados Unidos de América.

8 A diferencia de los demás escritores hispanocameruneses cuyas novelas o poemarios han sido publicados en casas editoriales o en revistas literarias, la producción literaria de Romual-Achille Mahop Ma Mahop es importante pero inédita: Un relámpago apenas y La mujer que no me hace.

9 La producción literaria hispanocamerunesa se expande en la parte reservada a la biobibliografía de cad escritor. Sin embargo, esta lista de obras literarias puede también cambiar en el futuro a medida que se profundicen las investigaciones sobre la literatura hispanocamerunesa.

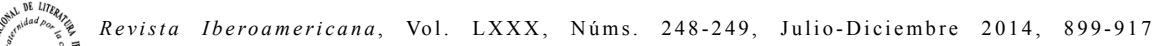
ISSN 0034-9631 (Impreso) ISSN 2154-4794 (Electrónico) 
(en España) y Alain Lawo-Sukam (en los Estados Unidos de América); y otros viven en Camerún como Céline Clémence Magnéché Ndé, Magloire Mol Nang, Robert Marie Johlio Germain Metamo y Romual-Achille Mahop Ma Mahop. Junto a aquellos escritores, está naciendo también una nueva generación de jóvenes escritores que se destacan por ganar premios literarios organizados por el Centro Cultural Españo de Yaundé: Williy Bris Kenmogne, ganó en el 2007 en la categoría de poesía sobre el tema "Desierto, sabana y bosque" (2007) y Daniel Claude Billé Kome, también resultó ganador en el concurso de prosa con bajoe el mismo pópico. En el 2008 Rodrigue Azébazé Boungo, resultó ganador del concurso de prosa con el cuento "La sabiduría de los mayores" (2008). Estos jóvenes constituyen el futuro de la literatura hispanocamerunesa si siguen el camino de la escritura y no desaparecen por razones socio-económicas o políticas.

Antes de adentrarnos en el análisis de la producción literaria de los escritores hispanoamericanos, es importante esbozar una sinopsis biobibliográfica de cada uno de ellos. Me limitaré sólo a los datos esenciales de cada uno. ${ }^{10}$

Germain Metanmo nació en Bafou el 1 de marzo de 1953. Cursó el Bachillerato en el colegio Saint Laurence de Bafou y realizó estudios en la Universidad de Yaundé, en la Universidad de Paris-Sorbonne y en Park Lane College of Further Education en Inglaterra. Se doctoró por la Universidad de Cheick Anta Diop de Dakar (Senegal) y obtuvo un diploma como traductor superior en el Instituto Universitario de Lenguas Modernas y Traductores de la Universidad Complutense de Madrid. Trabajó por un tiempo como catedrático de español en el Instituto de Nkongsamba y actualmente se desempeña como profesor titular de la Universidad de Dschang, es asistente en la Universidad de Yaoundé I y en la Escuela Normal Superior en la misma ciudad. Ejerce también la profesión de traductor intérprete. Es autor de El varón (1985), De voces de mi tierra (1999) y de obras inéditas como Cajón de sastre, Álbum familiar y Curiosidades de la lengua española.

Magloire Mol Nang nació en Nguiniouma el 2 de diciembre de 1953. Obtuvo la licenciatura en la Universidad de Yaundé y luego el D.E.A en Letras Hispánicas en la Universidad de Toulouse-Le Mirail (Francia). Se doctoró en Filosofía Hispánica por la Universidad Complutense de Madrid. Es profesor titular de literatura española e hispanoafricana de la Universidad de Yaundé I y profesor asociado de las universidades de Dschang y Duala. Escritor y crítico literario, es autor de La huérfana y otros cuentos (2004) e Historia de locos, obra todavía inédita.

Cécile Clémence Magnéché Ndé nació el 22 de octubre de 1967 en Dschang. Cursó en la Universaidad de Yaundé y se doctoró en Filología Hispánica por la Universidad

\footnotetext{
${ }^{10}$ Los datos biográicos han sido obtenidos de la antología Equinoccio (2007) realizada por Irina Razafimbelo y Guillermo Pié Jahn y de mis propias investigaciones.
}

de Zaragoza. Es profesora de lengua y literatura españolas en la Universidad de Dschang y trabaja también como responsable de un programa social en Penka Michel Ha publicado numerosos artículos en revistas como Paremia y Estudios de Literatura Oral. En 2004 publica en España su obra cuentística ¿Verdad que esto ocurrió? Cuentos orales africanos. Es autora de las obras inéditas Las luciérnagas de la noche, Tengo nombre y apellido y Noche Vieja.

Robert Marie Johlio nació el 16 de octubre de 1959 en Bangang. Obtuvo el bachillerato en el Instituto Clásico de Bafúsam y la licenciatura en la Universidad de Yaundé. Ingresó en la Escuela Normal Superior de Yaundé donde se graduó como catedrático de lengua y literatura españolas. Recibió becas de estudios para fomentar su educación en Valladolid y Madrid. Es inspector nacional de lengua española en el Ministerio de Educación de Camerún y profesor asociado en la Escuela Normal Superior de la Universidad de Yaundé I. Ha publicado cuantiosos artículos en revistas como Mula verde Review, El Patio y el Árbol del Centro. En 1998 publica la novela El esqueleto de un gigante, escrita junto con el español Pedro Pablo Viñuales.

Guy Merlin Nana Tadoun nació el 6 de octubre de 1974 en Ndoungué. Se graduó de la Universidad de Yaundé I con una licenciatura en Estudios Hispánicos. En la actualidad prepara su doctorado en la Universidad de Salamanca gracias a una beca de la Agencia Española de Cooperación Internacional (AECI). Fue Secretario del Centro Cultural de la Embajada de España en Camerún. Es miembro de "La Ronde des poetes du Cameroun". Es autor del poemario en francés Poesie du poeme (2002) y Horizontales (2005) en español. Tiene inéditos numerosos poemarios Brisa africana, Flores de febrero y Memoria del olvido, entre otros tantos, y dos novelas, Amores fusilados y Rumbo a Melilla.

Boniface Ofogo Nkama nació el 16 de enero de 1966 en Bogondo. Se licenció en Filología Hispánica por la Universidad de Yaundé. Luego obtuvo la Maestría en Literatura Hispanoamericana por la Universidad Paul Valéry de Montpellier en 1989. Se fue a España con una beca del AECI, se doctoró en Filología Hispánica, y obtuvo su especialidad en Literatura Hispanoamericana en la Universidad Complutense de Madrid en 1994. Trabajó como Intérprete Oficial del Foro Alternativo "Las otras voces del planeta" en Madrid (1994); fue técnico del Equipo de Educación Intercultural de COMRADE (de 1993 a 1994); miembro del comité de redacción de la Revista Sin Fronteras de 1994 a 1997. A partir de 1997 ha sido ponente en cursos de formación al profesorado sobre temas de Educación Intercultural; mediador intercultural en el ayuntamiento de Móstoles, Madrid de 1998 a 2001; ponente en el Máster "Migraciones y Relaciones Intercomunitarias" en la Universidad Autónoma de Madrid en 2001. En la actualidad se entrega de lleno a contar cuentos en festivales, simposios, cafés, bares, bibliotecas, y centros culturales en España. El año 2006 publicó en Madrid el libro Una Vida de cuento. 
Inongo-vi-Makomé nació en 1948 en Kribi donde cursó parte de sus estudios además de Ebolowa. Se trasladó a los 14 años a Fernando Poo donde siguió con sus estudios en el Instituto Santa Isabel. En 1970 decidió mudarse a España donde terminó el bachillerato en la Universidad de Valencia y luego ingresó a la Facultad de Medicina pero sin poder terminarla. Se mudó a Barcelona donde reside desde 1972, dedicándose a las actividades culturales. Fundó la compañía teatral "grupo Kribi” y es también director de la asociación Mfundi Kupa I Kribi-Itondi que promueve la tradición oral africana. En 2001 en Italia, obtuvo el premio Girula de Nápoles a la mejor dirección con Muna Anyambe. Su producción literaria abarca un número importante de obras entre las cuales se destacan los ensayos España y los negros africanos (1990) y La emigración negroafricana: tragedia y esperanza (2000); las novelas Rebeldía (1996) y Nativas (2008); los libros de cuento Bemama (1988) y Akono y Belinga: el muchacho negro que se transformó en gorila blanco (1988); las obras de teatro Emama (s.f) Muna Anyambe y Bwee o Ititi (2006), para citar sólo algunas.

Alain Lawo-Sukam nació el 17 de noviembre de 1973 en Bangwa (Camerún). Cursó los estudios en el Instituto Clásico de Bafúsam y luego en la Universidad de Yaundé I donde tuvo el privilegio de ser estudiante de los escritores Germain Metanmo y Robert Marie Jolhio. Obtuvo la licenciatura y la maestría en Estudios Hispánicos en la misma universidad. Colaboró con la Dra. Yanou Angele a administrar la pequeña Biblioteca Angaba cuya trascendencia radicaba en ser una de las pocas donde los estudiantes podían consultar textos hispánicos. Recibió una beca de estudios de la Universidad de Illinois en Urbana-Champaign (Estados Unidos de América) donde se doctoró en Estudios Hispánicos en el 2005. En la actualidad es profesor de Estudios Hispánicos y de la Diáspora Africana en la Universidad de Texas A\&M en Estados Unidos. Ha publicado una docena de ensayos sobre literatura latinoamericana, afrohispana y ecuatoguineana en revistas prestigiosas como Revista Iberoamericana Revista Hispánica de Literatura y Cultura, Revista de Estudios Colombianos, Hipertexto, The Latin Americanist, Hispania, Neophilologus, y Palara, para citar algunas. Es el autor del libro crítico Hacia una poética afro-colombiana: El caso del Pacifico (2010). Su producción literaria abarca las colecciones de poemas Cantos a África y Tres poemas publicadas por Afro-Hispanic Review en 2003 y 2004, así como "La voz del pueblo africano" publicado por El collar de la paloma en 2007. Acaba de someter para publicación el poemario inédito África mi África a Viajera Editorial de Buenos Aires.

La literatura hispanocamerunesa es heterogénea y eclética. Abarca tanto la prosa como la novela, el cuento, la poesía, el teatro y el ensayo. Al igual que sus pares franco o anglo camerunesa, la hispanocamerunesa se caracteriza por la hibridez literaria que se manifiesta en la intersección entre la tradición oral africana (bantú) y la estética europea (en este contexto la española). Los escritores se sirven del español como herramienta

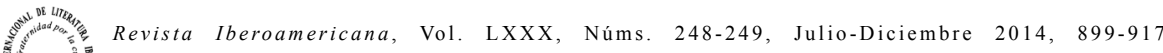
CDD ISSN 2154-4794 (Electrónico) lingüística para elaborar una narrativa didáctica y moralizadora influenciada por el uso de elementos de la tradición oral como las expresiones coloquiales, onomatopéyicas y los proverbios. De acuerdo con Fernando Lambert "El texto literario producido en estas condiciones particulares, posee características que los criterios de la crítica europea no han conseguido describir de forma satisfactoria porque el modelo europeo no es el único modelo de referencia" (citado en Ngom 113).

Las temáticas de la novela hispanocamerunesa giran en torno a la dialéctica del exilio/inmigración y de la representación de los usos y costumbres del pueblo tradicional Bamileké. Es un universo lleno de misterios y magia como es el mundo de Dante o Cervantes. El exilio es uno de los ejes temáticos recurrentes en la literatura hispanocamerunesa y africana en general. Este fenómeno se debe a razones políticas, educativas y económicas. Muchos son los cameruneses que se han exiliado en e extranjero por ser perseguidos a causa de sus opiniones políticas, por seguir con los estudios académicos y/o para escapar de la miseria económica que azota el país Después de pasar muchos años en el extranjero, algunos regresan a la cuna de sus ancestros para visitarla, quedarse o jubilarse. El fenómeno del exilio o del retorno del exilio engendra el cuestionamiento de la identidad personal, la colectiva y la naciona así como una (re)evaluación ideológica de la relación uni/bilateral entre la(s) metrópoli (s) y su antigua colonia (Camerún).

Rebeldía (1996), obra maestra de Inongo-vi-Makome, ilustra simbólicamente el conflicto interno y externo que traspasan el alma de los africanos que han emigado a Europa (España) por décadas y que inician el regreso a su tierra natal (Camerún). El narrador cuenta la historia de Essopi que dejó su tierra de origen para radicarse a Barcelona en busca de una mejor vida. Después de veinte años de estancia en la región catalana decide volver a Camerún para pasar algunas vacaciones. El viaje de regreso a la tierra natal (como el caribeño Aimé Césaire) se transforma en una crisis de identidad personal y colectiva. Por haber pasado casi un cuarto de siglo en España, Essopi se encuentra en una encrucijada existencial. La hibridez cultural que debería enriquecer su identidad se ha transformado en una experiencia traumatizante. Pertenece a dos mundos sin pertenecer a ninguno. Esta contradicción dialéctica y traumatizante ya lo expresó el crítico Juan Balboa Boneke:

¿Quién soy yo? ... Ni soy de aquí, ni soy de allá. Y cuando me descubro a mí mismo resulta que para mis hermanos (mi pueblo), soy un extraño. Sigo sintiéndome extraño en esta sociedad porque no acaba de sentirme comprendido, porque no acabo de comprender. (11)

En la búsqueda de su propia identidad, Essopi se topa con la dura realidad socioeconómica de su terruño. Esta realidad transforma el viaje de regreso en una diatriba contra las fuerzas imperialistas occidentales representadas por Francia, Inglaterra y

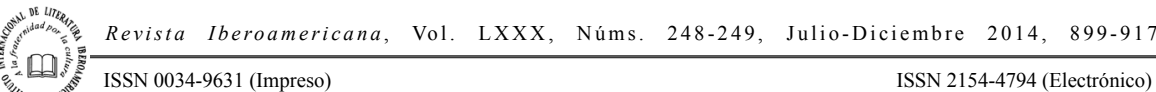


España que explotan al país y destruyen su medio ambiente. En este contexto la supuesta ventaja de escaparse del yugo del colonialismo (por la independencia) y de pertenecer a la época postcolonial/postindependencia se ve substituido, desafortunadamente, por el neocolonialismo. Esta situación provoca en el personaje principal una toma de conciencia nacionalista y afrocéntrica que contribuye a la reconciliación con su pueblo. La rebeldía contra el imperialismo europeo, la (re)centralización de África en e discurso universal, la reafirmación de la tradición ancestral y el humanismo constituyen, según Essopi, las herramientas para el desarrollo del país y del continente africano en general. Esta conceptualización ideológica se ubica dentro de los parámetros de la negritud cuya meta principal es la lucha antiimperialista y la valoración de la cultura africana como lo promovieron sus pioneros Aimé Césaire, León Damas y Leopold Seda Senghor. Para un mundo mejor, el humanismo y los valores comunitarios, tan arraigados en la cultura africana, deben reemplazar la deshumanización de la sociedad occidental dominada por el capitalismo alienante y devastador.

La crítica del egocentrismo occidental se hace explícita en los ensayos España y los negros africanos (1990) y La emigración negroafricana: tragedia y esperanza (2000) donde Inongo-vi-Makombe relata la tragedia y las congojas de los africanos que emigran a España y donde sufren el racismo, la pobreza y la persecución de las autoridades y la xenofobia del pueblo español. Para Inongo-vi-Makombe la recuperación de los valores ancestrales y de la memoria histórica constituyen una herramienta catalizadora de la lucha antiimperialista. La experiencia personal del escritor exiliado se convierte en una experiencia colectiva o grupal donde lo privado y lo público se confunden. Como afirma Antonio Muñoz Molina:

[Los escritores exiliados] se empeñan obsesivamente en rememorar el pasado, en reconstruirlo, en dar testimonio de lo que vivieron. [...] La mejor literatura del exilio es un gran empeño de recapitulación, una tentativa de comprensión del desastre, y en ella con frecuencia la memoria histórica personal desemboca en los sobresaltos del tiempo histórico, de modo que lo privado y lo público se confunden en un solo relato. (9)

Si Rebeldía de Inongo-vi-Makombe es una novela socio-políticamente compremetida El esqueleto de un gigante (1998) de Robert Marie Johlio enfoca el contexto cultural de la realidad africana.

La novela de Jolhio y de Viñuales cuenta la historia del narrador, un español que emprende un viaje a Camerún y acepta la invitación de Thomas a pasar el fin de semana en su pueblo Bangang y a asistir a unos funerales. El esqueleto de un gigante cabe dentro de la narrativa epistolar del viaje y de la mística en que el narrador penetra al mundo Bamileké regido por el vampirismo, las sociedades secretas y la demonomanía. Desde las primeras páginas del texto sobresale una temática común

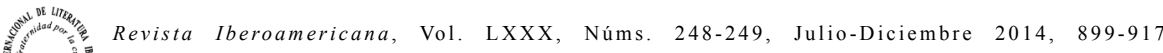
ISSN 0034-9631 (Impreso) en la novela de viaje en la literatura africana: el estereotipo/prejuicio racial. Si la experiencia del africano que viaja a Europa rebosa de incidentes raciales en que el negro se ve etiquetado con términos peyorativos y racistas, en el caso del blanco que viaja a África, es todo lo contrario. El narrador relata su experiencia con algunos niños cameruneses de la siguiente manera:

Ha sido una experiencia bastante extraña, que los niños me señalen y griten jel blanco!, ¡el blanco!, todo el mundo llamando la atención sobre mí, jeh mira un blanco!, jel hermano de Jesús!, o tomándome por americano: how do you do? [...] Al principio puede resultar gracioso, inofensivo, pero luego te va entrando un inevitable fastidio, la molestia de sentirte confundido en una imagen estereotipada, anónima, bajo la que difícilmente te reconoces. (19)

Al llamarle "blanco" al narrador, los niños negros lo hacen por curiosidad y no por menosprecio y con la intención de amenazar su vida. No lo equiparan con el diablo (como hacen los europeos con los negros) sino a la figura de Cristo por la afinidad racial. Aunque le causa molestia al narrador, el estereotipo en este contexto no es negativo ya que no intenta deshumanizar al individuo ni cuestionar su existencia.

A medida que el narrador se adentra en la sociedad Bamileké, descubre un universo paralelo al suyo donde se respeta mucho a los viejos y las tradiciones. Es un mundo basado en la unión y la solidaridad, cuya cultura sobresale por sus canciones, bailes tradicionales y la comida local dominada por verduras y vegetales como el "taró". El vivir cotidiano se expresa por medio de los proverbios y la historia de la humanidad que cuentan los ancianos o notables "griots". La organización administrativa del pueblo sorprende también al narrador. Es un sistema híbrido en que cohabitan dos poderes indisociables: el Estado y la Jefatura. La administración civil está en manos de un funcionario del gobierno y del alcalde cuando la jefatura la dirige el jefe del pueblo (el rey) con su consejo de sabios (notables). Siendo un pueblo animista y muy arraigado en la tradición ancestral, el pueblo honora y respeta más la institución tradicional que la gubernamental. A diferencia de los funcionarios y alcaldes que son nombrados por el presidente o elegidos por el pueblo, la sucesión del jefe tradicional o del rey es hereditaria y patriarcal. Esta estructura tradicional remonta a la época pre-colonial y ha sobrevivido al peso de la colonización.

Las prácticas funerarias a que asiste el narrador desestabilizan la concepción que tiene de la vida y la muerte. Parece encontrarse en el universo macondiano de García Márquez, donde lo mágico es tan real como la realidad es mágica. Este fenómeno se hace explícito en la muerte de una de las esposas de Ganlekán, uno de los notables del poblado:

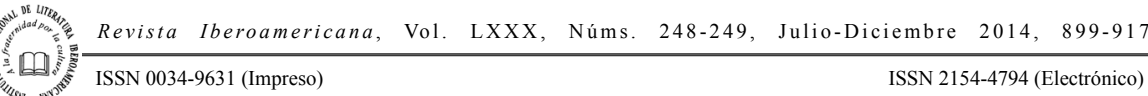


Aquello carecía de explicación admisible: una persona va caminando perfectamente erguida, con todo el peso de su carga y sin dar muestras de fatiga y de pronto se derrumba muerta [...] El problema se hubiera quedado en una muerte súbita [...] si un viejo avanzando hacia el interior del primer círculo y señalando al cadáver, no hubiera dicho con la voz quebrada: “ivampirismo!”. Los lamentos se convirtieron en murmullos. (40)

El término "vampirismo" en el contexto de la novela es una práctica maligna como lo define Thomas: "Los espíritus vampiros, que habitan en el sexo de las personas, tienen el poder de salir en la oscuridad para buscar la sangre de la que se alimentan. Su forma es similar a la de las lechugas" (44). Si para el narrador, la muerte de la esposa de Ganlekán se habría tratado de un derrame cerebral o un ataque cardíaco fulminante, según el pueblo no es natural sino mística y provocada por la brujería. La pluralidad de perspectivas (heteroglosia) simboliza el encuentro de dos culturas y dos visiones del mundo: la occidental y la africana.

Las costumbres maléficas del pueblo Bangang se manifiestan también en la existencia de las sociedades secretas cuyos miembros gozan de potencias negativas:

Los escasos miembros que la componen, de los más temibles, se bastan para comerciar con las almas de los vivos [...] La peculiaridad más creíble de este comercio fatal con lo invisible es que las muertes, de una manera u otra, deben darse dentro de la familia del brujo vendedor, quien está obligado, a intervalos más o menos regulares, a ofrece una víctima. Y no existe el arrepentimiento ya que de hacerlo, él mismo es ajusticiado por los demás componentes de su secta. (54)

El vampirismo y las sociedades secretas no son prácticas animistas exclusivas de los pueblos africanos sino que existían también en la época medieval (Frere). ${ }^{11}$

Lo metafísico se expresa también en la capacidad licantrópica de Ganlekán, quien tiene el poder de desdoblarse en un enorme cuervo (100). Y como advierte el anciano "¡Cuidado! No todos los animales son iguales. Entre ellos, en ocasiones, hay seres humanos especiales" (64). La fluidez entre el mundo animal y humano no entra en la lógica cartesiana sino que es común y corriente en la cultura Bamileké y africana. Sin embargo, este poder de asumir una forma animal no es la panacea de todo el mundo sino de los iniciados. La capacidad del ser humano de transformarse en animal no es nueva en la literatura occidental como lo demuestra Kafka en "La metamorfosis". Si la metamorfosis kafkiana pertenece al mundo surrealista, el caso de El esqueleto de un gigante se aparenta mucho más a lo real maravilloso de Alejo Carpentier.

"El tema sobre la demonología en el Esqueleto de un gigante ha sido analizada por Mbol Nang en "La demonología en el esqueleto de un gigante de Robert Marie Jolhio y Pedro Pablo Viñuales".

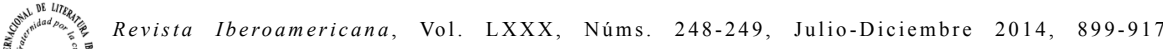
ICD
Aparte de la novela, la poesía es el género más usado por los escritores hiapanocameruneses. Ha sido catalogada ya en dos antologías: Equinoccio (2007) ${ }^{12}$ y El Carro de los dioses (2008). Es una poesía íntima, lírica, local y universal cuya temática está muy relacionada con el exilio, la subjetividad femenina, la naturaleza, la identidad y la condición del continente africano.

La experiencia del exilio se expresa en "La justicia de la distancia" de Nana Tadoum y "Un recado para los míos" de Metanmo, por la nostalgia hacia Africa como locus amenus que le permite al poeta escapar de la soledad existencial. Si en "La justicia de la distancia" el poeta encuentra la soledad lejos del continente africano, en "Un recado para los míos" el recuerdo de África constituye un remedio tanto al frío invernal como al racismo vigente en la sociedad española. Musita el poeta: "Díles a los míos que aquí el frío pela/ pero me calienta su cariño./[...] que en mi estómago el hambre no cabe/ pues miro hacia África, y me fortalece./ Al que se ríe de mi color yo le sonrío/ Me sacude la tormenta blanca/ y me vuelvo más negro" (40). La situación del inmigrante africano en España o en los Estados Unidos es muy compleja. Aunque sufren la soledad y la xenofobia, no tienen más remedio que soportarlas ya que la tierra del exilio ofrece ciertas ventajas, ya sea la educación o el trabajo, que no puede encontrar en su terruño. Este fenómeno se hace explícito en "Lejos de ti, Africa" de Lawo-Sukam donde la voz poética decide marcharse lejos de su tierra aunque lamenta su partida: "Lejos de ti/ sin ti/ enfrentar mi destino/ no puedo/ pero tengo que marcharme/[...]/ despojado de tu amparo/ en las aguas de mis ojos/ me siento aislado en mi dolor/ solitario me acosa la soledad/ pero tengo que marcharme/[...] No obstante/ de mi ida depende tu vida/ de mi viaje tu felicidad/" (69). Este poema resume la vida de millones de inmigrantes africanos que dejan el continente cada año para buscar una vida mejor en el Occidente. Aunque la salida a veces no es voluntaria, es necesaria ya que los medios financieros y/o la educación que recibe en el extranjero, le permite al inmigrante mejorar la vida de sus parientes (que se han quedado atrás en África) y la de la sociedad africana en general con las inversiones en los sectores económicos y culturales. Como lo corrobora Phillip Kurata en "African Migrants Invest in Their Home Countries": "With about 2 million to 3 million people migrating to rich countries annually, the potential influence of diaspora communities on business growth in developing countries is immense, World Bank economist Lev Freinkman wrote in 2002. Seven years later, his view has turned out to be prophetic".

Los poetas hispanocameruneses no se procupan sólo por la situación de la diáspora africana sino también meditan sobre la situación del país y del continente africano sacudidos por las guerras, la corrupción, el nepotismo y el neocolonialismo. En "El país" de Mol Nang, el poeta se lamenta de la miseria material de Camerún cuyos

\footnotetext{
${ }^{12}$ Los poemas citados en este artículo han sido obtenidos de la antología Equinoccio.
} 
recursos naturales han sido explotados por las potencias europeas antes y después de las independencias: "Era rico, rico, rico.../ Ahora es uno de los más pobres/ Qué pasó/ Leones hambrientos de/ Dinero/ Algún día pasaron por aquí. Todo lo mamaron, comieron, chuparon" (79). El contraste temporal entre el pasado opulento y el presente miserable indica el cambio radical que ha sufrido el país, cuyos recursos han sido saqueados por los gobiernos coloniales y después por las empresas occidentales. Los verbos mamar, comer y chupar expresan la explotación que ha sido y sigue siendo víctima el pueblo africano. Como hizo Antonio Machado en el caso de España, Mo Nang se interroga sobre el triste destino de su pueblo, pero no es el único. En "Ópera en los trópicos" Metanmo reflexiona sobre la tragedia que vive el continente africano y le horroriza su inercia a pesar de la riqueza que posee:

Me espanta el África hipnotizada./ La odio acomplejada y acorralada./ No es mía el África de las películas/ monstruo del espectáculo y del engaño./ No es mía el África muda, sin diálogo./ Me duele el África de los cotos vedados/ [...]/ Quiero a mi África polvorienta e inocente,/ primitiva pero genuina,/ con tatuaje y superstición/ África aséptica y sin sobornos/ Africa inmaculada y cortés/ que tenía fe y creía en el más allá/ África de tratos humanos, libre de dineros/[...]/África de bambú y paja olorosa/África de las hadas blancas y fortísimas emociones/ [...]/.África venerable de filósofos sin cátedra/[...]/ Te quieren porque hueles a tierra y a hombres/que no a hormigón, rascacielos, especulación./ Tú eres selvática pero no salvajes/ Paraíso perdido de la sabiduría/ tierra solidaria y hospitalaria/[...]/ÁAfrica de piel negra y corazón de oro/ nutre al mundo famélico, opulento pero miserable/ con canto de vida/ que musita tu alma milenaria. (43-45)

Uno se pregunta cómo un continente tan rico en recursos humanos y naturales puede ser tan pobre. Además del colonialismo y neocolonialismo europeos que arruinan e progreso del continente, se suman las dictaduras, las guerras y el despilfarro de los recursos naturales por el poder dominante o las autoridades africanas. Este fenómeno se hace explícito en "En la estera de la nada" donde Nana Tadoum denuncia el carácter dictatorial de la supuesta democracia de los países africanos. Dice el poeta: "La interminable guerra que no viene/ del entorno. Las avanzadas democracias/ que a veces huelen a monocracia indefinible [...] las dictaduras que el petróleo despinta y los niños,/ los niños sin ropa que a los cañones abandonan su rostro" (18). Estas dictaduras muchas veces surgen del deseo egoísta de monopolizar las riquezas del país en las manos del poder/élite dominante. Este egocentrismo político-económico ignora al pueblo que vive en la miseria, y que aquí se representa de manera metafórica con la imagen de los niños sin ropa. En vez de invertir el dinero del estado para desarrollar al pueblo, los dirigentes lo usan para llenar sus cuentas bancarias en el extranjero y comprarse palacios de vacaciones. En "Hombre rico entre los pobres" se lamenta

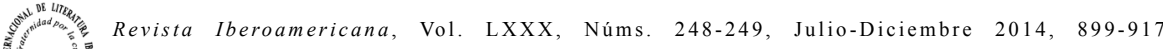
LDD
Lawo-Sukam: “Océanos y mares recorres / montes y valles desafías/ cofres en bancos ajenos/ con el oro desencallas/ Eso no está bien/Veleros y fincas posees, chalé, dúplex/ castillos levantas/ En tierras extranjeras/ para tu placer egoísta/[...]Algo de peso harás/ invirtiendo en tu tierra" (72).

$\mathrm{Al}$ dolor de la miseria física del continente africano, se yuxtapone la lucha por la subjetividad de la mujer negra. Eso se hace explícito en la poesía de Magnéché Ndé. En "Furor de vivir" la voz poética denuncia la opresión de la mujer en una sociedad patriarcal donde los hombres tienen control sobre el destino y los cuerpos femeninos:

¿Por qué adaptar nuestras apariencias a lo que quieres?/ ¿Por qué alimentarnos siempre con tu savia?/ ¿Por qué dejarnos siempre tus ojos y corazón?/ ¿Es que nuestro destino está para que siempre lo pisen? [...] Mírame tal como soy/ y no como quisieras que fuera $[\ldots]$. Tengo lo que hace falta/ para establecer mi destino:/ inteligencia, fuerza voluntad, imaginación./ Pero fortifícame/ fortifica mi espíritu. Algo de libertad./ Justicia./ ¡Libertad!/ !Libertad!/ Libertad, el aire que quisiera respirar/ Libertad, para ser lo que quisiera poder mirar sin miedo./ Libertad, para ser y parecer lo que soy./ Todos los días. (59)

Las preguntas retóricas sirven como estrategia discursiva para despertar las conciencias sobre la opresión física, psicológica y moral de que es víctima el género femenino a pesar de sus tantas habilidades intelectuales. El grito por la justicia y la libertad es una llamada revolucionaria contra las injusticias y el avasallamiento sexual no sólo en Camerún o África, sino también a nivel mundial. Eso se manifiesta en “¿Y si solamente me quedara esto?" en que la poeta revela el carácter universal de su lucha:

La vida. Simplemente./La de la campesina de Bánsoa;/ como la de la gitana de Granada;/ de la agricultora de Teze;/ del ama de casa de la calle de las Armas;/ de Rose, la profesora;/ de Francette, la secretaria./ Cuerpo llenos de dolor,/ miradas vacías y poco amenas,/cuerpos y almas enfermos. Sí. De injusticia. Enfermos de vivir sin vivir,/ enfermos del silencio implacable. (54-55)

Aunque la poeta no se adentra en los mecanismos y estrategias de lucha por la subjetividad femenina, comparte con las feministas del mundo las mismas preocupaciones por la injusticia y la desigualdad socio-económica y política a que están sometidas las mujeres.

En cuanto a los cuentos hispanocameruneses, oscilan entre la época precolonial y postcolonial. Son una compilación de los eventos mitológicos, de las historias orales/ folklóricas del pueblo, del encuentro entre el mundo occidental/ colonizador y africano/colonizado y por fin del vivir cotidiano del pueblo contemporáneo africano. Entre ellos se destacan "Bemama" (1988), "Akono y Belinga" (1988), "La huérfana y otros” (2004), “¿Verdad que esto ocurrió?” (2004), “Una vida de cuento” (2006) y “El

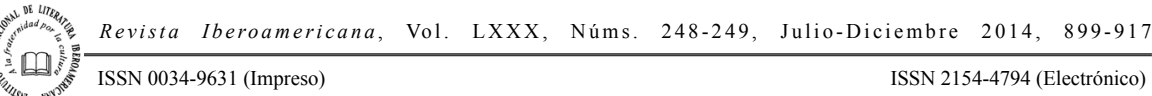


carro de los Dioses" (2008). Son cuentos didácticos /éticos, tanto infantiles como de adultos que dejan constancia de la tradición oral africana. Por ejemplo en " $i V e r d a d$ que esto ocurrió” de Magnéché Ndé, el cuentero les relata a los niños del pequeño pueblo Bansoa, la historia del continente donde existe una relación estrecha entre el ser humano, la naturaleza y los espíritus. Los niños se enteran, por ejemplo, de la razón por la cual la pantera es muy temible y la serpiente ayuda a los débiles. La moraleja que surge de los cuentos es la denuncia del egoísmo, de la malicia del ser humano así como de los problemas que conlleva la poligamia. Los cuentos hispanocameruneses están también llenos de humor y/o tragedia y en ellos el ser humano se animaliza tanto como el anima se humaniza/personifica. En "Bemama" de Inongo-vi-Makombe, el narrador cuenta el encuentro brutal y triste entre una tribu costera que tuvo que exiliarse en la selva durante años, huyendo de invasores extranjeros a los que califican de monstruos. Es una obra antiimperialista, anticolonial y anticapitalista como el relato "Akono y Belinga" en que la deshumanización del africano por el poder dominante europeo aniquila su capacidad creativa y su subjetividad. La imagen del personaje Belinga (quien se despierta y descubre que se ha convertido en un gorila) es una muestra del cambio radical que está ocurriendo en la sociedad africana neocolonizada donde el pueblo, antes dueño de su destino, se ha convertido de repente en un animal sin agencia, que puede oír sin actuar o defenderse. El conflicto entre la tradición y la modernidad está muy presente en los cuentos hispanocameruneses, como bien lo aclara Germain Metanmo en la voz del personaje "abuelito": "A modo de conclusión, el abuelito dijo: Ya veréis que hoy día vivimos en una situación de trastorno. No sabemos por dónde ir, ni si más vale seguir a los blancos o a nuestros antepasados" (80). El cambio profundo que ha generado la colonización del pueblo africano ha provocado una crisis existencial y un trastorno de las costumbres locales. El pueblo africano parece vivir una situación de exilio cultural interno. Esta situación de crisis que afecta al continente africano viene expresada también en el teatro hispanocamerunés.

Las obras teatrales son en su mayoría la labor de Inongo-vi-Makome, quien se ilustra con Emama, Muna Anyambe (2006) y Bwee o Ititi (2006). "Emama" significa "monstruo" cuyo plural es "Bemana" "monstruos". Emama es en general la historia cantada y bailada del continente africano. El personaje principal se mueve a lo largo de la historia, recorriendo narrativamente los tiempos de la esclavitud, de la colonización, de las independencias, guerras civiles, golpes de estado y las epidemias de SIDA. La obra invita a los africanos a emanciparse política, económica y culturalmente del Occidente y a luchar también contra los males sociales como la corrupción y las enfermedades.

En conclusión diremos que la literatura hispanocamerunesa forma parte de una nueva y creciente vertiente de la literatura en lengua española por autores oriundos de países que no han sido colonizados por España. El surgimiento de dicha literatura se debe en gran parte a la introducción del español como materia de enseñanza en

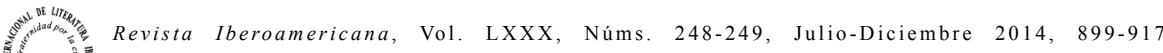
ISSN 0034-9631 (Impreso) los institutos y universidades por razones políticas, socio-económicas, culturales y religiosas. La literatura hispanocamerunesa en su conjunto brota de la experiencia existencial de sus autores y abarca tanto la prosa como los versos. Es una literatura de representación y de resistencia realista. Enfoca la realidad del vivir cotidiano no solamente del camerunés sino del africano y del ser humano en general. La temática del exilio, el neocolonialismo, la injusticia, la miseria y la subjetividad de la mujer y de la naturaleza no se limitan al espacio geográfico camerunés sino que al mundial. Es también una literatura que puede relacionarse con la de los clásicos del mundo europeo y latinoamericano en cuanto al desarrollo de la temática de la magia y/o lo metafísico que domina la narración en La divina Comedia, La Celestina, El Quijote o el Fausto de Goethe o lo real maravilloso y el realismo mágico en El reino de este mundo y Cien años de soledad. El estudio de la literatura hispanocamerunesa y de la literatura en lengua española en los países no-hispanos en general abre una nueva perspectiva sobre la (re)definición de la literatura hispánica y del mundo hispano en su conjunto.

OBRAS CITADAS

Balboa Boneke, Juan. ¿Dónde estás Guinea? Palma de Mallorca: Imprenta politécnica, 1978.

Chakor, Muhammad y Sergio Macías. Literatura marroquí en lengua castellana. Madrid: Magalia, 1996.

Frere, Jean-Claude. Las sociedades maléficas. El diablo, ayer y hoy. Barcelona: Ediciones Martínez Roca, 1982.

Godínez Gonzales, Fátima. "El Español en Camerún”. Enciclopedia del Español en el Mundo. Madrid: Instituto Cervantes, 2006. 63-69.

Jolhio, Robert Marie y Pedro Pablo Viñuales . El esqueleto de un gigante. Malabo: Ediciones Centro Cultural Hispano-Guineano de Malabo, 1998.

Klor de Alba, Jorge. "The Postcolonization of the (Latin)American Experience: A Reconsideration of 'Colonialism', 'Postcolonialism' and 'Mestizaje'." After Colonialism: Imperial Histories and Postcolonial Displacements. Gyan Prakash, ed. Princeton: Princeton UP, 1995. 241-75.

Kurata, Phillip. "African Migrants Invest in Their Home Countries." Engaging the World. America.gov. (6 nov. 2009). <http://www.america.gov/st/developenglish/2009/November/20091106173018cpataruk0.2806055.html>. 18 abril 2010.

Lambert, Fernando. "Antropophagie culturelle et décolonisation du texte literaire africain." CJAS/RCEA XXII/2 (1988): 291-301.

Lawo-Sukam, Alain. "Cantos a Africa (Collection of poems)." Afro-Hispanic Review 22/1 (2003): 68-74.

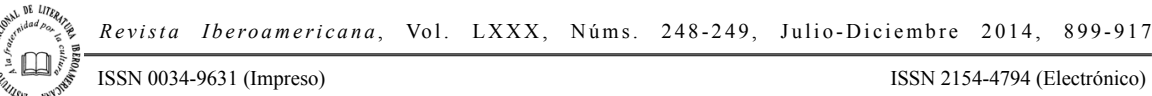


"La voz del pueblo africano (Collection of poems)." El collar de la paloma. (2007) <elcollardelapaloma.net/21.html>.

"Tres poemas" Afro-Hispanic Review 23/1 (2004): 36-37.

López Gorgé, Jacinto. Nueva antología de relatos marroquíes. Granada: Port-Royal, 1999.

Magnéché Ndé, Cécile Clémente. ¿Verdad que esto ocurrió?: cuentos orales africanos. Madrid: Páginas de espuma, 2004.

Metanmo, Germain. Hijo Varón. Nkongsamba: (s.e), 1985.

Curiosidades de la lengua española (En relación con el Francés). Yaundé: (s.e; s.f).

Voces de mi tierra. Yaundé: (s.e), 1999.

Mol Nang, Magloire. La huérfana y otros cuentos. Madrid: Mundo negro, 2004.

Muñoz Molina, Antonio. Prólogo. "Nubes atravesadas por aviones: la novela fantasma de Paulino Masip". El diario de Hamlet García de Paulino Masip. Madrid: Visor, 2000. 7-12.

Nana Tadoun, Guy Merlin . Horizontales. Yaoundé: Editions de la Ronde, 2005.

Nang, Mbol. "La demonología en el esqueleto de un gigante de Robert Marie Jolhio y Pedro Pablo Viñuales". epos XX-XXI (2004-2005): 101-13.

Ngom Fayé, Mbare. Diálogos con Guinea. Panorama de la literatura guineoecuatoriana de expresión castellana a través de sus protagonistas. Madrid: Labrys 54, 1996.

Ofogo Nkama, Boniface. Una vida de cuento. Madrid: MEC. Colección Palabras con voz, 2006.

Onomo-Abena, Sosthène y Joseph-Désire Otabela Mewolo. Literatura emergente en español: literatura de Guinea Ecuatorial. Madrid: Ediciones del Oro, 2004.

Pié Jahn, Guillermo e Irina Razafimbelo. "El español en Madagascar". Enciclopedia del Español en el mundo. Madrid: Instituto Cervantes, 2006. 93-96.

Razafimbelo, Irina y Guillermo Pié Jahn. Equinoccio. Poesía hispanocamerunesa. Las Palmas de Gran Canarias: Puentepalo, 2007.

El Carro de los Dioses. Las Palmas de Gran Canarias: Puentepalo, 2008.

Vi Makomè, Inongo. Akono y Belinga: el muchacho negro que se transformó en gorila blanco. Barcelona: El Crit de l'Oliba, 1988.

Benama (Monstruos). Barcelona: El crit de l'Oliba, 1988.

Bwee o Ititi (Una lucecita en la oscuridad). París: L'Harmattan, 2006.

Emama (s.f)

España y los negros africanos. Barcelona: La llar del llibre, 1990.

La emigración negroafricana: tragedia y esperanza. Barcelona: Carena, 2000.

Muna Anyambe (La hija de Dios). París: L’Harmattan, 2006.

Nativas. Barcelona: El Clavel, 2008
Población negra en Europa. Segunda generación, nacionales de ninguna nación. San Sebastián: Gakoa, 2002.

Rebeldía. Barcelona: Biblària, 1996.

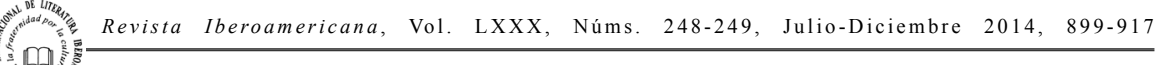


